Gut, 1966, 7, 671

\title{
Clinical and radiological study of vagotomy and gastric drainage in the treatment of pyloric stenosis due to duodenal ulceration
}

\author{
HAROLD ELLIS, F. STARER, C. VENABLES, AND C. WARE \\ From the Professorial Surgical Unit and Department of Radiology, \\ Westminster Hospital, London
}

EDITORIAL COMMENT Twenty-one patients with pyloric stenosis treated by vagotomy and gastric drainage have been followed up clinically and radiologically for periods of between nine months and five years from operation. Results are uniformly good and the method is advocated as the surgical treatment of choice for this condition.

Although vagotomy combined with gastric drainage is now a well-established procedure in the surgical treatment of duodenal ulcer, it has been suggested by a number of authorities that it is contraindicated in those cases which are complicated by pyloric stenosis (Moore, Chapman, Schulz, and Jones, 1947; Bergin and Jordan, 1959; Kraft, Fry, and DeWeese, 1964; Mialaret, 1964; Capper, 1965.)

After vagotomy, gastric mobility is diminished as a result of the loss of extrinsic nerve supply to the stomach; subsequently it is partially restored through a peripheral motor mechanism mediated by the intrinsic nerve plexus in the stomach wall (Dragstedt, Harper, Tovee, and Woodward, 1947). It has been argued that the decompensated musculature of the stomach, dilated as a result of pyloric obstruction, might be more susceptible to the atonic influence of vagotomy (Bergin and Jordan, 1959) and that prolonged gastric atony is likely to follow this operation.

This paper presents a clinical and radiological study of 21 patients with gross pyloric stenosis due to duodenal ulceration, all of whom were treated by vagotomy combined either with gastro-jejunostomy or pyloroplasty. The immediate and long-term clinical results were satisfactory in all 21 cases. Subsequent barium meal series in 20 of these patients showed that the dilated stomachs had returned to normal tone and size with satisfactory emptying. From this investigation it is argued that vagotomy and gastric drainage, far from being contraindicated, is the treatment of choice in this condition.

\section{CLINICAL STUDY}

The clinical review comprised 21 consecutive patients with gross pyloric stenosis due to duodenal ulceration operated on by members of the Professorial Surgical Unit at Westminster Hospital from nine months to five years previously (Table I). Seventeen of the patients were male and four female, and their ages, at time of operation, ranged between 34 and 72 years (Table II).

TABLE I

FOLLOW-UP AFTER VAGOTOMY AND DRAINAGE

\begin{tabular}{lc} 
Length of Follow-up & No. of Cases \\
\hline 9 months + & 3 \\
1 to 2 years & 4 \\
2 to 3 years & 4 \\
3 to 4 years & 4 \\
4 to 5 years & 6 \\
Total & 21
\end{tabular}

TABLE II

AGE DISTRIBUTION

\begin{tabular}{lc} 
Age Group & No. of Cases \\
\hline 30 to 39 & 4 \\
40 to 49 & 5 \\
50 to 59 & 9 \\
60 to 69 & 2 \\
70 to 79 & 1 \\
Total & 21
\end{tabular}

Clinically, diagnosis was based on the presence of one or more of the following features: projectile vomiting (particularly if food was noted which had 
been eaten the previous day), the presence of a gastric splash heard four hours or more after the last meal, visible gastric peristalsis or a gastric residue of $500 \mathrm{ml}$. or more. Radiologically, all patients had the typical and gross features of gastric outlet obstruction (Kreel and Ellis, 1965) and the diagnosis was confirmed in every case at laparotomy.

Before operation, a week or more would be employed in restoring electrolyte imbalance, cleansing the stomach by daily or twice daily gastric lavage with normal saline, and attention both to dental hygiene and to protein and vitamin replacement.

The policy at operation was to perform a pyloroplasty if at all technically possible. Should, as was often the case, the duodenum prove to be so inflamed, stenosed, or buried in adhesions that pyloroplasty might prove hazardous, a gastro-jejunostomy was performed. Post-operatively the oesophageal tube which had been passed into the stomach at the commencement of the operation to assist mobilization of the oesophagus and ensure complete gastric emptying was removed, no subsequent naso-gastric suction was employed and small amounts of fluid by mouth were allowed as soon as consciousness had returned.

Sixteen of the patients underwent a total abdominal vagotomy combined with gastro-jejunostomy, which was of the posterior short afferent loop type, placed vertically at the gastric antrum. Four patients had a total abdominal vagotomy combined with a pyloroplasty of the Weinberg type, 7.5 to $10 \mathrm{~cm}$. in length. One patient had an anterior selective vagotomy (with preservation of the hepatic branches) combined with pyloroplasty. Since we could find no obvious differences between these groups at followup, and in particular because of the small numbers concerned, we shall not detail the type of drainage in the subsequent analysis of the clinical study.

At review each patient was closely questioned about his alimentary function, care being taken to avoid leading questions.

In all patients the appetite was uniformly good; any type of food could be eaten in normal amounts. Only one patient had had further vomiting; when interviewed two years after vagotomy and gastrojejunostomy he remarked on three such isolated episodes each year, although he was otherwise perfectly well. Dumping symptoms, that is to say, weakness, faintness, or sweating after meals, were absent in this series. Three patients had the same weight as on admission to hospital pre-operatively; others had gained up to $2 \frac{1}{2}$ stone in weight. In effect, all the patients had achieved or surpassed their former weight before the onset of stenosis and weight gain was particularly marked in those patients in whom loss during the period of stenosis had been most profound (Table III).
TABLE III

WEIGHT CHANGE

\begin{tabular}{lc} 
Weight Change & No. of Case \\
\hline Unchanged & 3 \\
Gained up to $\frac{1}{2}$ stone & 4 \\
Gained $\frac{1}{2}$ to 1 stone & 1 \\
Gained 1 to 2 stone & 6 \\
Gained 2 to $2 \frac{1}{2}$ stone & 7 \\
Total & 21
\end{tabular}

A close enquiry was made into each patient's bowel habits before and after the operation (Table IV). At the time of review, 11 of the patients were passing a single motion a day, although one of these was having episodes of diarrhoea once a month comprising two or three loose stools daily for two days. Eight patients were passing between one and two motions a day, one three motions a day, and one between three and four motions daily. Compared with before the operation, one patient was passing stools less frequently than before, nine had the same frequency and 11 were more frequent, but nine of these latter, in fact, were having only one bowel action daily. The patient who was having occasional episodes of diarrhoea was mildly inconvenienced by this. Six patients had no particular comment to make on their bowel actions, but no less than 14 were pleased or even delighted about the change in their bowel habits because of the preceding constipation which is so often a marked complaint in patients with pyloric stenosis. This additional agreeable feature included the patient who was now having his bowels open three times daily.

\begin{tabular}{|c|c|c|c|}
\hline & $\begin{array}{l}\text { TAB I } \\
\text { WEL FR }\end{array}$ & $\begin{array}{l}\text { E I V } \\
\text { QUENCY }\end{array}$ & \\
\hline Frequency & $\begin{array}{l}\text { No. of } \\
\text { Cases }\end{array}$ & Patients' Comments & $\begin{array}{l}\text { No. of } \\
\text { Cases }\end{array}$ \\
\hline Daily & & & \\
\hline$\times 1$ & 11 & Pleased & 14 \\
\hline 1 to 2 & 8 & Indifferent & 6 \\
\hline & 1 & Mild displeasure & 1 \\
\hline 3 to 4 & 1 & & \\
\hline $\begin{array}{l}\text { Frequency comp } \\
\text { operation }\end{array}$ & fore & & \\
\hline Less frequent & 1 & & \\
\hline Same & 9 & & \\
\hline More frequent & 11 & & \\
\hline
\end{tabular}

During the period under review there was no operative mortality in the treatment of duodenal stenosis, nor indeed in over 200 consecutive cases of vagotomy with drainage for non-stenosed duodenal ulcers on this unit apart from one fatality from pulmonary embolism in an old lady in her eighties operated on as a semi-emergency following a massive haematemesis. 


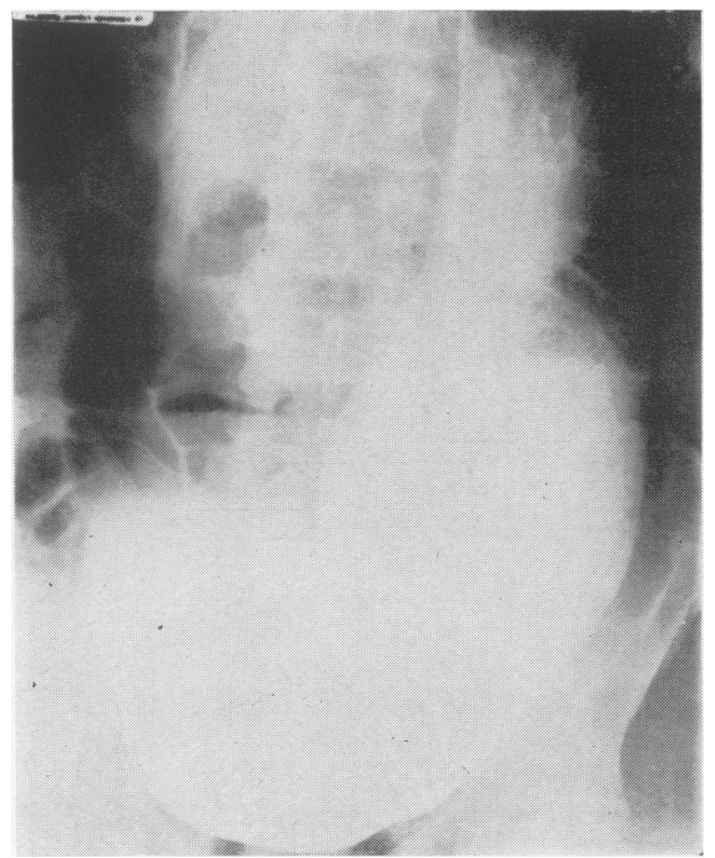

FIG. 1a. Pyloric stenosis with gross gastric retention.

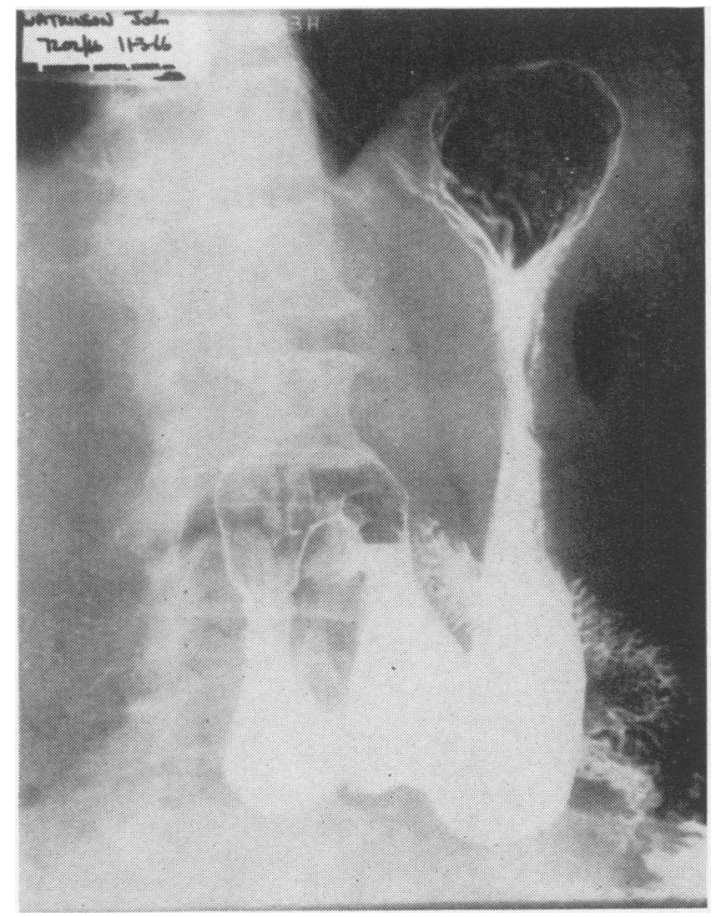

FIG. 1b. Same patient. Appearances three and a half years after vagotomy and pyloroplasty. Note the characteristic pseudo-diverticulum on the greater curve aspect of the antrum.

\section{RADIOLOGY}

All patients had barium meals performed before operation; in many cases these were done at the referring hospital and therefore a variety of techniques were used. Since the diagnosis was beyond doubt the examination was not repeated before operation, but the available films were carefully scrutinized.

For post-operative assessment, however, astandard

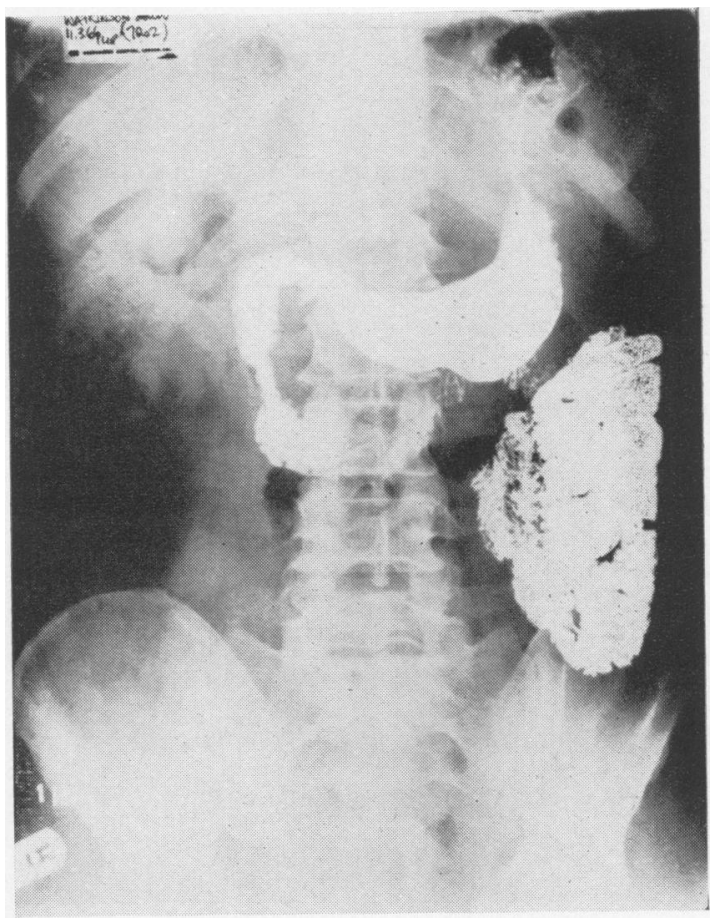

FIG. 1c. Film at one hour shows a moderate but not abnormal residue in the stomach.

technique was employed. The patient was given $3 \mathrm{oz}$. of neat Micropaque. Films of the stomach were taken in the prone, supine, and erect positions, with additional spot films, with and without compression, of the duodenum and of the gastro-enterostomy. A further film of the abdomen was taken at one hour to assess gastric emptying.

In all patients the radiological appearances were judged to be satisfactory. Gastric emptying was within normal limits, there was no evidence of anastomotic ulceration and no complications of any type were found. The improvement in gastric emptying in many of these patients was truly impressive. Figures $1(a, b$ and $c)$ and $2(a, b$ and $c)$ show the appearances of the stomach before and after opera- 
tion. In the patients who had had gastro-enterostomies performed, emptying of the stomach commenced immediately, and very little or no barium was left in the stomach at the end of one hour. In eight of these patients barium left the stomach both through the duodenum and the gastro-enterostomy; in the remaining eight, all or nearly all the barium passed through the anastomosis and hardly any through the duodenum. In the patients with pyloroplasties the stomach was empty or virtually so at

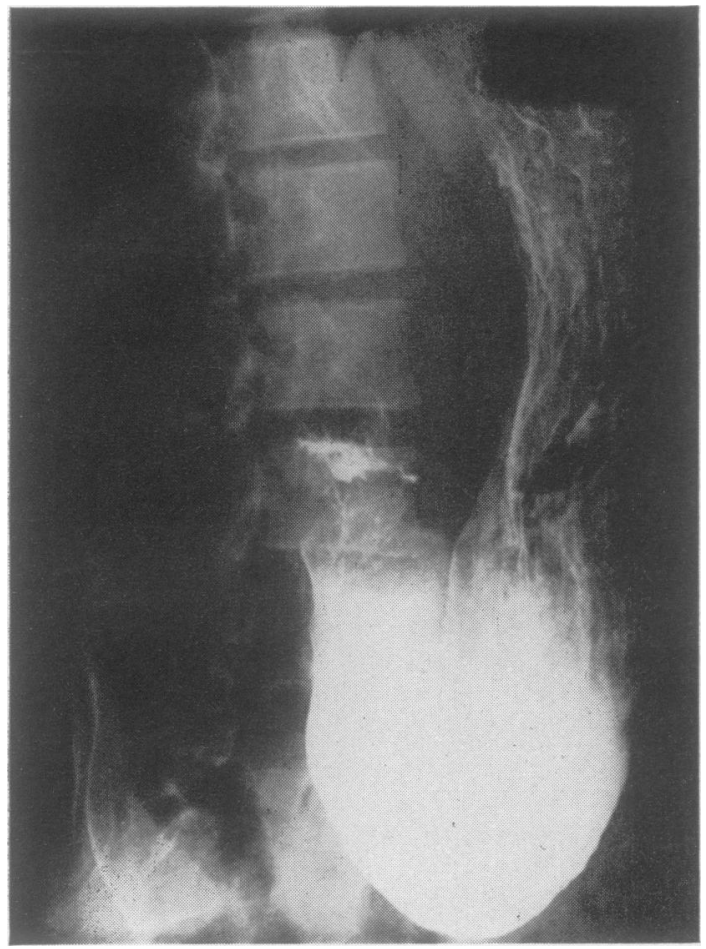

FIG. 2a. Pyloric stenosis with marked gastric retention. Pre-operative appearances.

one hour in three cases; in the remaining two a moderate amount of barium was still present at that time (Fig. 1c). This might suggest that pyloroplasty is a little less effective as a drainage operation than gastro-enterostomy but the numbers are too small to allow any valid conclusions, particularly when it is remembered that there is considerable variability in emptying rates in different patients, and in the same patient at different times. The amount of barium remaining in the stomach in the two pyloroplasty patients was certainly not abnormal, and the result must be regarded as satisfactory.

Two of the patients with pyloroplasty showed pseudo-diverticula at the site of operation (Fig. 1b) and one had some resting gastric juice present.

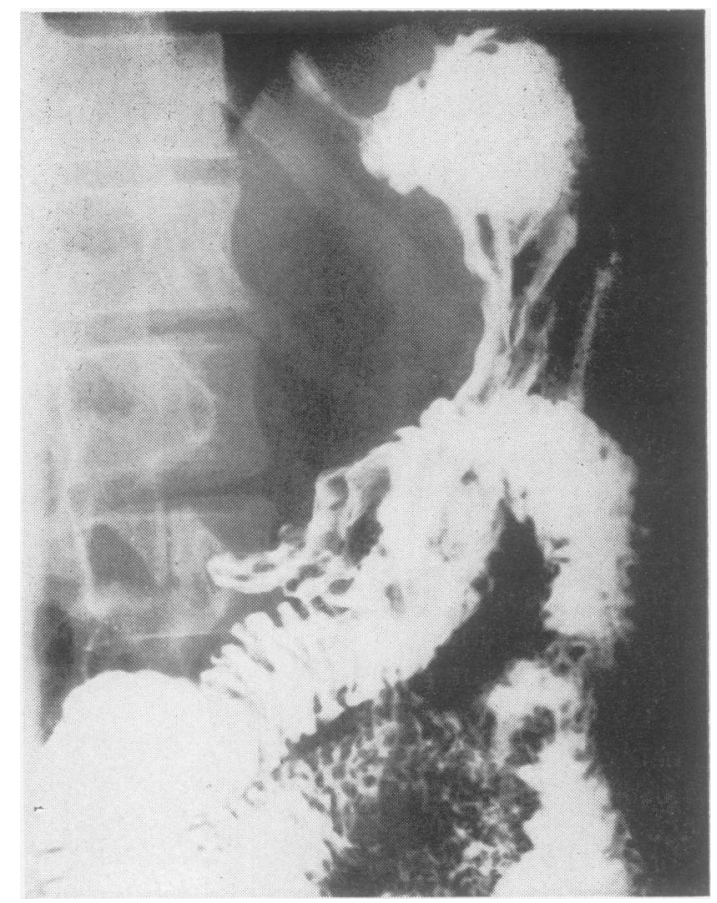

FIG. 2b. Appearances three years following vagotomy and gastroenterostomy. The stomach has completely regained its tone.

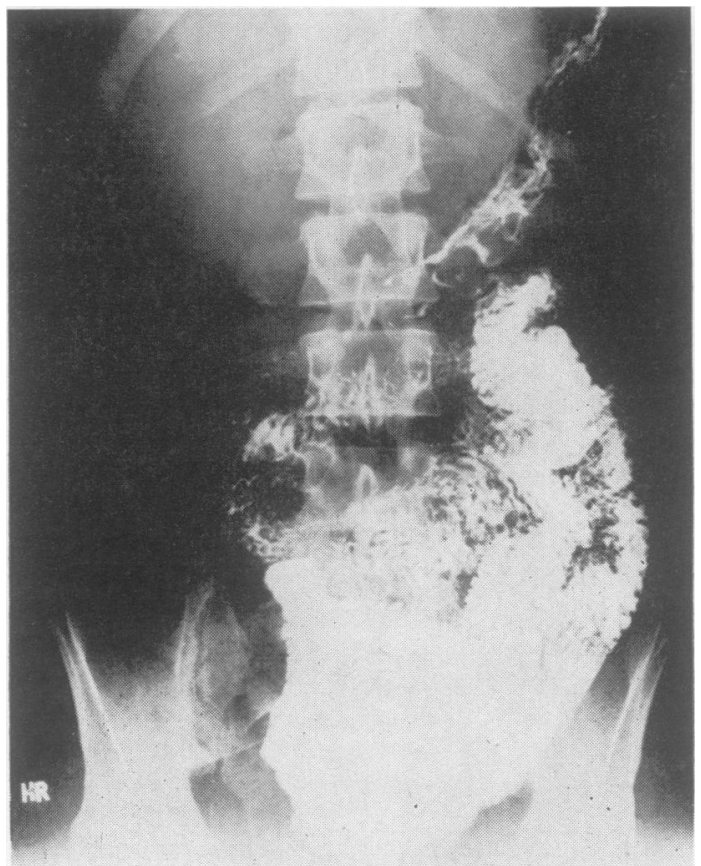

FIG. 2c. Film at one hour shows virtually complete emptying of the stomach. 
No cineradiographic studies were carried out on these patients but visual observation of gastric peristalsis revealed no abnormalities and, despite theoretical considerations to the contrary, vagotomy seems to have had little effect on gastric motor activity.

\section{DISCUSSION}

Although pyloric stenosis is a common complication of duodenal ulceration, and in spite of the fact that many tens of thousands of vagotomies have now been performed, surprisingly little has been published on the clinical results of this procedure in pyloric stenosis and still less on the radiological changes that take place in the dilated stomach following vagotomy.

Bergin and Jordan (1959) compared 32 patients with stenosis treated by a vagotomy combined with drainage procedure with 42 similar cases treated by gastric resection only. In the vagotomized group, eight patients had gastric retention for more than 10 days following operation, compared with not a single example of this complication in those treated by gastric resection only. Moreover, in a further 44 unobstructed cases treated by vagotomy and drainage, again there was no example of gastric retention. Kraft et al. (1964) studied patients with duodenal ulceration treated by gastrectomy, by vagotomy combined with hemi-gastrectomy and by vagotomy and drainage. The cases were divided into those who were not obstructed and those with established pyloric stenosis. In the unobstructed patients, the incidence of post-operative gastric retention existing for 14 days or more was respectively $3 \%, 9 \%$, and $5 \%$ in the three procedures. In the cases with pyloric stenosis, the incidence was $0 \%, 9 \%$, and $27 \%$ respectively. Because of this high incidence of postvagotomy gastric atony in the patients with pyloric stenosis treated by vagotomy and drainage, these authors also strongly advised against this procedure in the care of such cases and advocated gastric resection. It should be noted that the long-term results of the vagotomized patients who developed gastric atony in the post-operative period was satisfactory; six out of seven achieved a good, and one a fair, result.

In contrast, Smith (1964) reported uniformly satisfactory results with 27 patients treated by vagotomy and pyloroplasty for stenosis and encountered no problem of post-operative gastric retention. Feggetter and Pringle (1965) could find no difference in long-term follow-up between patients operated upon because of failed medical treatment and those whose indications for surgery were the serious complications of duodenal ulceration, i.e., perforation, haemorrhage and stenosis, who had been treated by vagotomy and gastro-jejunostomy. Of 41 patients with stenosis thus treated who were studied 10 to 14 years later, 28 had excellent and six had good results. Two patients were improved and there had been five failures (two stomal ulcers, one gastric ulcer, one carcinoma, and one tuberculous gastritis). Thirty patients with stenosis complicated either by haemorrhage, perforation, or both of these, gave the following long-term post-operative results: 20 were excellent, seven good, two improved, and there had been one failure due to recurrence of the duodenal ulceration.

In our own small group of patients submitted to vagotomy with drainage for stenosis, prolonged gastric retention was not encountered; indeed, nasogastric aspiration was never required in the postoperative period. Gastric retention occurred in only one patient among over 200 with non-obstructed duodenal ulcers treated in our unit by vagotomy and either pyloroplasty or gastro-jejunostomy during this period. He was an Egyptian aerophagist in whom gastric aspiration had to be continued for three weeks befose satisfactory emptying occurred. Two years later he reported himself fit and free from symptoms.

The causes of prolonged delay in gastric emptying after stomach surgery are complex and still far from completely understood. This complication may occur after gastrectomy, gastro-jejunostomy, or pyloroplasty whether or not these are combined with vagotomy. Recognized mechanisms include metabolic disturbances (especially potassium or protein depletion), paralytic ileus, oedema, dysfunction or fibrosis of the stoma, thickening and adhesion of adjacent mesocolic or omental fat, high small bowel obstruction and jejuno-gastric intussusception. These have been well reviewed by Mathieson (1965) and by Stammers and Williams (1963).

Our long-term results, admittedly only taken to a maximum of five years after operation, were uniformly good. All the patients were well satisfied with the operation and there was only one who was less than entirely pleased, this on account of monthly episodes of mild diarrhoea. In this assessment we are supported by the longer review of a larger series of patients reported by Feggetter and Pringle (1965) already quoted above.

Turning now to the radiographic features, Bloch and Wolf (1965), using cineradiography, were able to demonstrate a moderate decrease in motor activity in the gastric antrum in many of their patients following vagotomy and pyloroplasty. In view of the normal variability in peristalsis a much larger series than ours would be required to confirm this. Further, peristalsis in the stomachs of our patients was likely to have been abnormal before operation, and they would 
therefore not be suitable for 'before-and-after' comparisons. Bloch and Wolf's patients were studied sooner after operation than ours and this might also make a difference since the stomach may recover some of its activity with time. From a practical point of view it can be said that there was no delay in gastric emptying and no significant change in gastric motor activity as observed by the radiologist following the operations carried out on our patients.

Relatively little has so far been written on the radiological appearances following pyloroplasty. Like others we have found surprisingly little change in the appearance of the antrum in these patients (and in others not included in this series). Of the present five patients, only two showed the pseudo-diverticula described by Burhenne (1964) (Fig. 1b), and one patient had resting gastric juice in the stomach, a finding also mentioned by Bloch and Wolf (1965). None of these findings appears to have any influence on the result as far as the patient was concerned. A much larger number of pyloroplasties would have to be studied before any meaningful correlation can be made between the details of operative technique, radiological appearances of the antrum, and the success of the procedure.

Our radiological studies indicate how difficult it is to comment on the state of the duodenal cap in these patients. The scarring of the duodenum is often so severe that detection of an ulcer would be extremely difficult, even in those in whom the duodenal cap filled adequately. The diagnosis of recurrent duodenal ulceration, should this occur, would be very tricky but an anastomotic ulcer could no doubt be demonstrated in the usual way.

\section{REFERENCES}

Bergin, W. F., and Jordan, P. H., Jr. (1959). Gastric atonia and delayed gastric emptying after vagotomy for obstructing ulcer. Amer.J. Surg., 98, 612-616.

Bloch, C. and Wolf, B. S. (1965). The gastroduodenal channel after pyloroplasty and vagotomy: a cineradiographic study. Radiology, 84, 43-51.

Burhenne, H. J. (1964). Roentgen anatomy and terminology of gastric surgery. Amer. J. Roentgenol., 91, 731-743.

Capper, W. M. (1965). Post-vagotomy gastric atony. Med. Annu., 54.

Dragstedt, L. R., Harper, P. V., Jr., Tovee, E. B., and Woodward, E. R. (1947). Section of the vagus nerves to the stomach in the treatment of peptic ulcer. Complications and end results after four years. Ann. Surg., 126, 687-708.

Feggetter, G. Y. and Pringle, R. (1965). The relationship between the severity of duodenal ulceration and the results of bilateral vagotomy and gastrojejunostomy. Brit. J. Surg., 52, 691-693.

Kraft, R. O., Fry, W. J., and DeWeese, M. S. (1964). Postvagotomy gastric atony. Arch. Surg., 88, 865-874.

Kreel, L. and Ellis, H. (1965). Pyloric stenosis in adults: A clinical and radiological study of 100 consecutive patients. Gut, 6, 253-261.

Mathieson, A. J. M. (1965). Prolonged delay in gastric emptying after partial gastrectomy. Its management with particular reference to stomal dysfunction. Brit. J. Surg., 52, 657-663.

Mialaret, J. (1964). In La Vagotomie dans l'ulcère Gastro-duodénojejunal, edited by A. G. Weiss and L. F. Hollender. Expansion Scientifique Française, Paris.

Moore, F. D., Chapman, W. P., Schulz, M. D., and Jones, C. M. (1947). Resection of the vagus nerves in peptic ulcer: physiologic effects and clinical results, with a report of two years' experience. J. Amer. med. Ass., 133, 741-749.

Smith, G. K. (1964). In discussion to Kraft et al. Arch. Surg., 88, 872.

Stammers, F. A. R. and Williams, J. A., eds. (1963). Partial gastrectomy: Complications and Metabolic Consequences. Butterworths, London. 